University of Warwick institutional repository: http://go.warwick.ac.uk/wrap This paper is made available online in accordance with publisher policies. Please scroll down to view the document itself. Please refer to the repository record for this item and our policy information available from the repository home page for further information.

To see the final version of this paper please visit the publisher's website. Access to the published version may require a subscription.

Author(s): ANN ADAMS, CHRISTOPHER D. BUCKINGHAM, SARA ARBER, JOHN B. MCKINLAY, LISA MARCEAU and CAROL LINK Article Title: The influence of patient's age on clinical decision-making about coronary heart disease in the USA and the UK Year of publication: 2006 Link to published version: http://dx.doi.org/ 10.1017/S0144686X05004265 Publisher statement: None 


\title{
The influence of patient's age on clinical decision-making about coronary heart disease in the USA and the UK
}

\author{
ANN ADAMS*, CHRISTOPHER D. BUCKINGHAM†, \\ SARA ARBER**,JOHN B. MCKINLAY $\dagger \dagger$, \\ LISA MARCEAU $+\dagger$ and CAROL LINK $\dagger^{\dagger}$
}

\begin{abstract}
This paper examines UK and US primary care doctors' decision-making about older (aged 75 years) and midlife (aged 55 years) patients presenting with coronary heart disease (CHD). Using an analytic approach based on conceptualising clinical decision-making as a classification process, it explores the ways in which doctors' cognitive processes contribute to ageism in health-care at three key decision points during consultations. In each country, 56 randomly selected doctors were shown videotaped vignettes of actors portraying patients with CHD. The patients' ages (55 or 75 years), gender, ethnicity and social class were varied systematically. During the interviews, doctors gave free-recall accounts of their decision-making. The results do not establish that there was substantial ageism in the doctors' decisions, but rather suggest that diagnostic processes pay insufficient attention to the significance of older patients' age and its association with the likelihood of co-morbidity and atypical disease presentations. The doctors also demonstrated more limited use of 'knowledge structures' when diagnosing older than midlife patients. With respect to interventions, differences in the national health-care systems rather than patients' age accounted for the differences in doctors' decisions. US doctors were significantly more concerned about the potential for adverse outcomes if important diagnoses were untreated, while UK general practitioners cited greater difficulty in accessing diagnostic tests.
\end{abstract}

$\boldsymbol{K E} \boldsymbol{Y} \boldsymbol{W} \boldsymbol{O R} \boldsymbol{D} \boldsymbol{S}$ - ageism, primary health care, coronary heart disease, classification, decision-making, cognitive processes, health inequalities.

\section{Introduction}

Improving older people's experiences of health and social care is a concern in the United Kingdom (UK) and in the United States of America

* Centre for Primary Health Care Studies, University of Warwick, Coventry, UK.

$\dagger$ Computer Science, Aston University, Birmingham, UK.

** Centre for Research on Ageing and Gender, University of Surrey, Guildford, UK.

$\dagger \dagger$ New England Research Institutes, Watertown, Massachusetts, USA. 
(US). In both countries, recent policy has set out targets for high quality, patient-centred and integrated health and social care services, with the aim of promoting and prolonging healthy, independent living for older people and rooting out age-based inequality (Department of Health $(\mathrm{DoH})$ $2000 a$, 200I; National Institute of Aging 2000; Audit Commission 2002). If these aims are to be achieved, it is important to focus attention on older people's initial contacts with health and social care systems, for it is these that identify patients' problems and instigate interventions. This process usually begins within primary care consultations, the quality of which plays a key role in determining older people's subsequent pathways through health and social care service provision (DoH 2002).

This paper examines the influence of age on primary care doctors' clinical decision-making and the extent to which ageism is present. Much previous research has focused on the influence of patient and doctor characteristics on the outcomes of clinical decisions, but this paper elucidates their association with doctors' cognitive processes. We have argued elsewhere that different theories of decision-making and different approaches to decision analysis can usefully be conceptualised as components of the psychological classification process that lead to diagnosis and treatment decisions (Buckingham and Adams 2000 $a, 2000 b$ ). This approach is applied to British and American primary care doctors' accounts of the decisions they make about older and middle-aged patients who present with symptoms of coronary heart disease (CHD). The focus is on the micro-processes of doctors' clinical decision-making and how these are affected by the patient's age, but the paper also examines the wider healthcare system influences.

A literature review on age-based rationing and indirect ageism in health care in relation to CHD is first reported. The classification process for modelling clinical decision-making is then introduced, followed by a description of the analytic model and study methods. A number of hypotheses for empirical testing are formulated and explained, and finally the findings and the extent to which they evince age-bias are discussed.

\section{Defining ageism in health care}

The likelihood of ill health, including CHD, increases with age (Priebe 2000), and it is well known that older people consume more health-care resources than other age groups (Roberts, Robinson and Seymour 2002). CHD is of major public health significance in both countries, and accounts for a sizeable proportion of both middle-aged and older people's health-care expenditure. In the US it is a leading cause of mortality and 
hospitalisation in people aged 65 or more years (National Centre for Health Statistics 2002). It has been consistently identified as the greatest single cause of premature death in the UK, and is a key target for health improvement (DoH I99I, I998, 2000 $b$ ). Health-care providers are however faced by a dilemma; on the one hand, they are required to root out ageism, while on the other, they are subject to close performance management against externally prescribed objectives and targets (Glendinning, Coleman and Rummery 2002).

A survey by Age Concern England (2000, 2002) has suggested that a common consequence of the dilemma is age-based rationing of health care, and the organisation has argued that both direct and indirect ageism exists in health care. Direct ageism occurs where policies specifically state that goods and services are unavailable to people of a certain age, thus making it clearly observable and identifiable. Indirect ageism occurs when practitioners' or organisations' ageist attitudes and assumptions inform decision-making and service provision, as when older people are seen as having lower priority than younger people and are therefore less likely to receive the care they need. This form of ageism is subtle and often covert or invisible, and very often individuals and organisations practise it unawares, making it difficult to challenge. Levy (200I) argued that every person who has internalised the age stereotypes of their culture is likely to engage in implicit ageism, and it is for this reason that much ageism is hidden. Such arguments highlight the inherent difficulty of achieving the aim of the National Service Framework (NSF) for Older People (DoH 200I), to provide health care on the basis of clinical need alone and regardless of age. This paper is a contribution to the specification and exposure of indirect ageism.

\section{Indirect ageism and clinical decisions}

While ageism processes are not well understood, age has many times been shown to influence inappropriately the outcomes of clinical decisionmaking. Historically, negative stereotypes of older people have been noted consistently in studies of practising US doctors, medical students and other health-care workers (Tarbox, Connors and Faillace I987; Johnson et al. ı986; Kwiteck et al. ı986; Black, Sefcik and Kapoor ı990; Carmel, Galinsky and Cwikel 1990). There is also evidence that health-care professionals are likely to categorise older people's health complaints as 'normal' concomitants of ageing rather than signs of illness (e.g. Haug and Ory I987), and that these negative attitudes are associated with differential treatment decisions (McLaughlin, Soumerai and Wilson 1996). Recent 
evidence from the UK demonstrates that older people are less likely than younger people to be offered health-promotion advice in primary care (Little et al. 1999).

With particular reference to CHD, McKinlay, Potter and Feldman (I996) demonstrated that while older patients presenting to primary care doctors were more likely to be diagnosed as having CHD than younger patients with identical chest pain symptoms, the higher probability of diagnosis did not give older patients more access to appropriate care interventions. It has also been shown that, compared with younger patients, older patients receive both delayed and fewer diagnostic interventions (Gatsonis et al. 1995, Shaw et al. 1996, Bond et al. 2003), fewer prevention drugs (Stafford and Singer I996), fewer prescriptions that are known to be effective cardiac treatments (Soumerai, McLaughlin and Speigelman 1997), and have more limited access to specialist care facilities (Dudley and Burns 1992). The evidence about ageism in CHD treatment in both countries, coupled with its public health significance, makes it an important clinical condition to examine in primary care. Comparing practice in two sharply contrasting contexts - the free enterprise, largely privatised US primary health care system, and the nationalised, government-funded UK system - enables the ways in which various social, organisational, and financial elements of health care either restrain or exacerbate ageism to be identified. The next section will consider how their effects can be detected through the psychological processes of clinical decision-making.

\section{Clinical decision-making as classification}

Building on earlier work (Buckingham and Adams $2000 a$, 2000 $b$ ), we have developed a detailed psychological model of clinical decision-making during primary care consultations. The model identifies three linked decision tasks: the formulation of diagnoses, the assessment of the potential outcomes if diagnoses are untreated, and the prescription of interventions. The general process is shown schematically in Figure I and accords well with existing descriptions of consultation processes (e.g. Cole and Bird 2000; Silverman, Kurtz and Draper I998; Neighbour I987; Hamm 2003). Each of the three types of classification tasks requires doctors to identify relevant cues, such as patients' age and their symptoms, and to integrate this information in the determination of the diagnostic, outcome and intervention classes to which the patient belongs. Each allocation has an associated level of certainty or confidence, which is again based on the integration of the available evidence. By decomposing this complex 


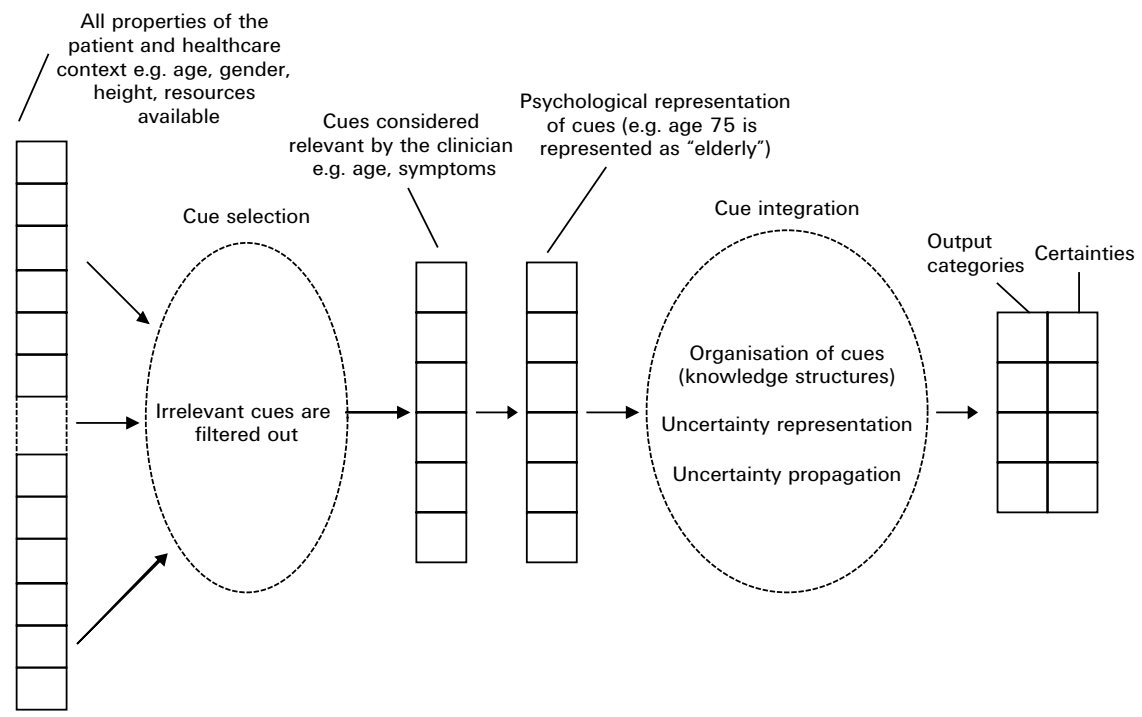

Figure I. A psychological model of clinical decision-making as a classification process.

process into its constituent parts, a heuristic and practical mechanism is provided for revealing the psychological elements of clinical decisionmaking. It permits the identification of links between doctors' behaviour and the particular stages of decision-making at which ageism may emerge, as well as health care system influences on these processes.

The paper applies the classification model to doctors' diagnostic and intervention decisions, to investigate whether different processes are used for older compared with midlife people with symptoms of CHD, and what influences those differences. The classification model itself indicates the factors that may make the decision-making prone to age-bias: the factors that influence classification; the knowledge structures used by doctors (explained later); and how doctors' use of knowledge structures and influential factors affects their certainty of the allocations. Using the classification model, we derive a number of hypotheses and explain how they are tested for age-related bias, but first the study methods are described.

\section{Study methods and sample design}

The qualitative data about primary care doctors' decision-making were collected through a large cross-national study with a factorial experimental 
T A B L E I. The quota combinations of patient characteristics in the experiment

\begin{tabular}{lll}
\hline Patient attribute & Categories \\
\hline Age & 55 years & 75 years \\
Gender & Male & Female \\
Race & White & Black (Afro-Caribbean) \\
Social class/occupation & Janitor/cleaner & School teacher \\
\hline
\end{tabular}

Note: The combinations of patient characteristics were represented in $16\left(2^{4}\right)$ different videos.

design that enabled the effects of doctor, patient and health service characteristics to be controlled (Cochran and Cox 1957). The study was conducted simultaneously in the United States (Massachusetts) and the United Kingdom (Surrey/South London and the West Midlands), to estimate the non-confounded effects of patient characteristics on the different types of decisions made by the primary care doctors. These included diagnostic, test ordering, treatment and referral decisions in the treatment of patients manifesting symptoms strongly suggestive of CHD and depression.

Professional actors were employed to represent patients with key symptoms of CHD in realistic portrayals of primary-care consultations that were videotaped. The method had been used successfully by the team in previous research on primary-care decision-making (McKinlay et al. 1997, 2002; McKinlay, Potter and Feldman 1996) and by others (e.g. McKinstry 2000). The scenarios were systematically varied by the simulated patient's age, race, gender, socio-economic status (SES) and American or British accent (see Table I). The 'patients' were either 55 or 75 years of age; either white or black (African-American in the US and Afro-Caribbean in the UK); and their SES was either middle class (retired/school teacher) or working class (retired/cleaner). Measures were taken to ensure the ecological and external validity of the scenarios for both countries, and to ensure that identical clinical information was portrayed by each 'patient'. For example, the doctors who participated in the experiment were shown a simulated consultation in their surgeries during normal working hours, were instructed to see the videoed patients as their own, and to make their care decisions taking into account local constraints. (They were also asked to assess how typical the scenarios were; 92 per cent said either 'reasonably' or 'very' typical).

The participating US primary-care doctors were randomly sampled from the Massachusetts Medical Society list, and the UK doctors from National Health Service regional Health Authority lists. The achieved sample of 256 doctors was respectively 65 per cent and 60 per cent of the 
T A B L E 2. Number of primary care doctors in the experiment by gender, year completed medical training and location of practice

\begin{tabular}{|c|c|c|c|c|c|}
\hline & \multirow[b]{2}{*}{$\begin{array}{l}\text { Year } \\
\text { CMT }\end{array}$} & \multicolumn{4}{|c|}{ Location of doctors' practice } \\
\hline & & $\begin{array}{c}\text { Massachusetts, } \\
\text { US }\end{array}$ & $\begin{array}{l}\text { Surrey and SE } \\
\text { London, UK }\end{array}$ & $\begin{array}{l}\text { West Mid- } \\
\text { lands, UK }\end{array}$ & All \\
\hline \multicolumn{6}{|c|}{ Male doctors } \\
\hline Older & I965-I979 & 32 & I6 & I6 & 64 \\
\hline Younger & I989-1996 & $3^{2}$ & I6 & I 6 & 64 \\
\hline \multicolumn{6}{|c|}{ Female doctors } \\
\hline Older & I965-I979 & 32 & I6 & I6 & 64 \\
\hline Younger & I989-1996 & $3^{2}$ & I6 & I6 & 64 \\
\hline All & & I 28 & 64 & 64 & 256 \\
\hline
\end{tabular}

Note: CMT: Year completed medical training.

eligible doctors initially approached in the US and UK. The sample was stratified by country (US and UK), gender and years of clinical experience (see Table 2).

All 256 doctors agreed to view a video of a simulated consultation, and afterwards were asked structured questions about their diagnoses and treatment decisions. A stratified random one-half of the sample ( $\mathrm{N}=$ I28) were then invited to give a free, unprompted account of their decisionmaking processes in response to the scenario. This approach allowed the doctors to articulate their thoughts in an unstructured way, thereby providing information not usually available about what, in their minds, was most significant about the video presentations, and about how their thoughts developed as they formulated their final conclusions. The analysis of these 'cognitive' data is the focus of this paper. The free recall opportunity was followed by further semi-structured questions about cognitive reasoning processes. Together, these were designed to elicit information about the doctors' uncertainty representation and knowledge structures involved in diagnosis (classification task I) and in assessing the potential outcomes (classification task 2), and thirdly, to gauge the influence of non-clinical factors on their intervention decisions (classification task 3). Missing and incomplete data meant that II2 (out of the I28) accounts could be analysed. These were provided by 56 doctors in each country and referred to $5^{6}$ patients aged 75 years and $5^{6}$ aged 55 years, thus constituting a dataset that was balanced in the variables of interest.

The doctors' accounts of their cognitive processes were tape-recorded, transcribed verbatim, and coded by themes that reflected the components of the classification model of clinical decision-making. This iterative process of developing the coding framework embraced not only all of 
the important theoretical decision-making components, but also ensured sufficient flexibility to identify additional concepts in the data. The interrater reliability of the coding of the free recall data (between AA and CDB) reached go per cent agreement. The next section describes the hypotheses tested to examine age-related bias, and provides more detail about the codes and how they were developed from the data. The relationships between these data and attributes of the patients, doctors and health-care system were explored, and analyses of variance tested the significance of effects.

\section{Hypothesis testing for age-related bias}

There were six main hypotheses, some of which were broken down into subsidiaries. Hypotheses I-4 refer to classification task I (generating differential diagnoses), Hypothesis 5 refers to classification task 2 (assessing potential outcomes if diagnoses are left untreated) and Hypothesis 6 refers to classification task 3 (determining interventions). Several of the hypotheses were constructed as null hypotheses for age-bias: if they were supported, there was no evidence that ageism had influenced doctors' practice. Each is described and justified, and explanations of the tests and results are provided below. Summaries of the results are presented in Tables $3^{-5}$.

\section{Hypothesis I: There is no difference between the number of cues considered by doctors for midlife and older patients}

When only a small set of patient cues are considered, this may lead to fewer and less well-developed diagnostic hypotheses, and creates the potential to miss important ones. Every mention of a patient cue was coded and the number of distinct cues counted. If consultations with older people generate fewer cues than consultations with midlife patients, it indicates that less attention has been given to their case and a potential for doctors to miss important factors in diagnosis and care prescriptions. The mean number of recalled cues was ir.7 (Table 3), and analysis of variance revealed no statistically significant differences by patients' age $(p<0.05) .{ }^{1}$ Hypothesis I was therefore accepted.

Hypothesis 2: The 'age' cue is equally influential in doctors' decision-making accounts for older and midlife patients

Age is a legitimate clinical cue because the likelihood of certain diseases varies with age (e.g. Priebe 2000). One would expect it to be more evident in doctors' accounts of decision-making with older people because 
T А в L E 3. Tests of differences in doctors' decision-making about midlife and older patients

\begin{tabular}{|c|c|c|c|c|}
\hline \multirow[b]{2}{*}{$\mathrm{H}$} & \multirow[b]{2}{*}{ Indicator or variable } & \multicolumn{2}{|c|}{ Patient age } & \multirow{2}{*}{$\begin{array}{c}\text { Statistical } \\
\text { significance }\end{array}$} \\
\hline & & 55 years & 75 years & \\
\hline & & \multicolumn{3}{|c|}{ Mean frequencies } \\
\hline I & Discrete cues & II.89 & II. $57^{1}$ & NS \\
\hline $2 . \mathrm{I}$ & Frequency of age cues & 0.77 & $0.9 \mathrm{I}$ & NS \\
\hline 2.2 & Age associations with inferences & 0.70 & 0.75 & NS \\
\hline 3 & Diagnostic inferences & 4.70 & $4.7 \mathrm{I}$ & NS \\
\hline $4 . I$ & Prototype occurrences & $0.70^{1}$ & $0.48^{2}$ & 0.02 \\
\hline 4.2 & Exemplar occurrences & 0.90 & 0.83 & NS \\
\hline $4 \cdot 3$ & Frequency/probability references & 0.50 & 0.43 & NS \\
\hline 5 & Potential outcomes considered & I. 45 & I.6I & NS \\
\hline 6 & Healthcare system constraints affecting decisions & 0.75 & I.OO & NS \\
\hline
\end{tabular}

Notes: H: Hypothesis number (see text). 95 per cent confidence intervals: i. o.57-0.82. 2. o.36-0.6 I.

of their increased likelihood of disease. Two subsidiary hypotheses were tested:

Hypothesis 2.I: There is no difference by age of patient in the number of times that the age cue is mentioned

Every mention of age was counted. The expectation was that the frequency would be higher in consultations with older patients because age had more clinical significance. It was found that 7I per cent of doctors mentioned patients' age during decision-making, but analysis of variance revealed no statistically significant age-group difference (the mean frequencies of mentions were 0.77 and $0.9 \mathrm{I}$ for midlife and older patients respectively). Less-experienced doctors mentioned the patient's age more frequently than more experienced colleagues $(82 \%$ versus $6 \mathrm{I} \%$, $p=0.0065$ ), but again analysis of variance revealed no statistically significant differences by patient age. Hypothesis $2 . I$ was therefore accepted.

Hypothesis 2.2: There is no association between the frequency of age cues and specific diagnostic inferences

The coding method grouped the cues with associated diagnostic inferences, i.e. the diagnosis the doctor associated with the cue at that point of the account. Hypothesis 2.I referred to all age cues, but Hypothesis 2.2 only to the age cues associated with specific inferences, e.g. a doctor saying a patient is the right age and type of person to have a gall bladder problem. It instances age being used as a specific influence on decision-making rather than being noted as a general patient attribute. Since the likelihood of disease increases with age, one would expect more age-related 
inferences for older patients. It was found, however, that although there was variation in the type of age-related inferences made for each group, (cancer was inferred more frequently for older patients and mental health problems for midlife patients), the mean number of inferences was not significantly different ( 0.7 and 0.75 for midlife and older patients respectively). Hypothesis 2.2 was therefore accepted.

\section{Hypothesis 3: There is no difference in the number of diagnostic inferences considered by doctors for older compared with midlife patients}

There is an increased likelihood of co-morbidity in older patients (e.g. Laukkanen et al. 1997). This implies that to allow for the greater variety of realistically applicable diseases among older patients, a correspondingly higher number of distinct diagnostic inferences should arise. Increased inferences indicate that the clinician has a more open mind to different possibilities. Any diagnostic inference made by doctors was coded and the totals recorded. Analysis of variance showed a mean of 4.7 diagnostic inferences per consultation, but no statistically significant differences by the age group of the patients. Hypothesis 3 was therefore accepted, suggesting that the likelihood of co-morbidity amongst the older age group may be being overlooked by primary-care doctors.

Hypothesis 4: Doctors' use of sophisticated pattern-recognition approaches when making diagnostic decisions is the same for older and midlife patients

Older patients tend to display atypical disease presentations (Priebe 2000; Gregoratos 2001; Abdelhafiz 2002; Jarrett et al. 1995) which can mean that CHD may not be recognised until an acute myocardial infarction occurs (Tresch and Alla 200I); and even this is sometimes missed (Gregoratos 200I). If clinicians are not properly aware of the predisposition for atypicality, delays in correct diagnosis and appropriate treatment can occur (Jarrett et al. 1995; Priebe 2000). Recognising atypical disease presentations requires sensitivity to cue patterns, which depends on the knowledge structures used by clinicians to represent disease classes. Two ways of representing knowledge about patterns of cues in 'disease class members' are to use prototypes and exemplars (Hampton I993). A prototype is an abstraction, a representation of a class by a single, most typical member, while the exemplar represents a class by all their known members (or those that have been encountered). The difference is important for two reasons. The first is that a prototype does not incorporate information about disease class sizes or prevalence, as does an exemplar. Failing to take account of prevalence means that the prior probabilities of diseases and outcomes are potentially ignored, and this 'base-rate bias' means the likelihood of rare diseases is exaggerated, with potentially serious 
clinical implications (for a review see Koehler I996; see also Dawes I983). It is possible that clinicians who rely on the prototype model are more prone to base-rate investigation bias. In clinical terms, prototypes relate to classic textbook descriptions of diseases and of typical disease patterns.

The second difference between a prototype and an exemplar is that the exemplar holds more information on the variability among its class members by retaining the various manifestations of the relevant patient cues. This may enable more unusual symptom patterns to be correctly matched to a doctor's disease representation and thus facilitate more appropriate interventions. The exemplar approach is important for older patients because of their higher prevalence of co-morbidity and atypical disease presentations. The problem, however, is that using exemplars makes higher demands on doctors' memory and cognitive processes. It is possible that the shortening of consultation times, as has been the trend, may encourage more use of prototypes, and increases the possibility of more unusual hypotheses being missed. It is therefore important to identify the pattern-matching knowledge structures that doctors use, particularly the mix of exemplar and prototype approaches. To identify the prototypes and exemplars that the doctors used, codes of the interview data were developed to distinguish 'disease knowledge in general' (a prototype) and 'experience of previous particular patients' (an exemplar). Three subsidiary hypotheses were developed to examine the doctors' use of pattern-recognition models of disease presentation.

\section{Hypothesis 4.I: There is no difference between the use of prototypes for midlife and older patients}

Doctors were asked if their diagnostic certainties were influenced by how closely the videoed patient's symptoms matched textbook descriptions of their diagnoses, and their answers of 'yes', 'no' or 'somewhat' were recorded. The interview transcripts were also analysed to identify the number of times 'classical' disease descriptions were mentioned as influences on the decision-making, and the results were used to validate the doctors' responses to the direct question about drawing on textbook descriptions of diagnoses. The two sets of data were synthesised. When textbook knowledge was paramount, it was interpreted as indicating prototypical representations. An analysis of variance confirmed that decisions about midlife patients were more likely to be informed by stereotypical, textbook presentations of diagnoses than decisions about older patients (mean scores 0.7 and 0.48 respectively). Hypothesis 4.1 was therefore rejected. 
T A в L E 4. Doctors' use of exemplars in decision-making about midlife and older patients by country and patient age

\begin{tabular}{|c|c|c|c|c|c|}
\hline \multirow[b]{3}{*}{ Statistic } & \multicolumn{4}{|c|}{ Country and patients' ages } & \multirow{3}{*}{$\begin{array}{c}\text { Statistical } \\
\text { significance }\end{array}$} \\
\hline & \multicolumn{2}{|c|}{ United States } & \multicolumn{2}{|c|}{ United Kingdom } & \\
\hline & 55 years & 75 years & 55 years & 75 years & \\
\hline Mean frequency & 0.97 & 0.70 & 0.80 & 0.95 & \\
\hline $95 \%$ confidence interval & $0.84-\mathrm{I} . \mathrm{IO}$ & $0.57^{-0.83}$ & $0.67-0.92$ & $0.82-1.08$ & 0.002 \\
\hline
\end{tabular}

Note: The test refers to Hypothesis 4.2 (see text).

Hypothesis 4.2: There is no difference between the use of exemplars for midlife and older patients

The participating doctors were asked if their diagnostic certainty was influenced by how closely the videoed patient's symptoms matched those of actual patients that they had encountered, and their answers of 'yes', 'no' or 'somewhat' were recorded. The interview data were also analysed to enumerate the number of times that the doctors referred to their experiences of actual patients as they made their decisions; the count was seen as an indicator of using exemplars of disease classes. Repeating the procedure for prototypes, these results were used to validate the doctors' responses to the direct question about drawing on experiences of previous patients, and the two sets of data were synthesised (Table 4). The results revealed insignificant differences in the use of exemplars by patients' age (mean scores of 0.9 and 0.83 for midlife and older patients respectively). There was, however, a significant interaction effect between patients' age and country $(p=0.002)$. US doctors were significantly more influenced by previous patients when assessing the certainty of diagnoses for midlife patients when compared with older patients (mean scores of 0.97 and 0.70 respectively). There was no difference in the frequency with which UK doctors recalled previous patients by age group of the consulting patients. Hypothesis 4.2 was therefore rejected for US doctors, but accepted for UK doctors.

Hypothesis 4.3: There is no difference in the use of probabilistic information between midlife and older patients

Reasoning with reference to prototypes does not necessarily imply no use of base-rate or prevalence information, because supplementary knowledge may be applied (e.g. Kruschke and Johansson 1999). To recognise this possibility, the coding scheme recorded explicit statements about class frequencies, probabilities or prevalence, e.g. a doctor might make a 
T a в L E 5. Differences in US and UK doctors' decision-making

\begin{tabular}{|c|c|c|c|c|c|}
\hline \multirow[b]{2}{*}{ Hypothesis and indicator } & \multicolumn{2}{|c|}{ United States } & \multicolumn{2}{|c|}{ United Kingdom } & \multirow[b]{2}{*}{$p$} \\
\hline & No. & $95 \%$ CI & No. & $95 \%$ CI & \\
\hline $\mathrm{H}_{5}$ : Potential outcomes considered & I.9I & I. $46-2 \cdot 36$ & I.08 & $0.64^{-I} \cdot 5^{2}$ & o.OII \\
\hline H6: Health-care system constraints & 0.33 & $-0 . \mathrm{II}-0.77$ & I. 39 & $0.82-1.08$ & 0.001 \\
\hline
\end{tabular}

Note: No. is the mean frequency of occurrences. CI: confidence interval.

statement like 'in middle-aged men there is a much higher incidence of hypertension amongst blacks than whites'. Such statements are evidence of doctors' decision-making being anchored in empirical evidence about disease prevalence. There is no reason to expect that a patient's age influences doctors' use of such evidence, and indeed the results found insignificant differences between the two patient age groups (mean scores of 0.5 and 0.43 for midlife and older patients respectively). Hypothesis 4.3 was therefore accepted.

Hypothesis 5: There is no difference between midlife and older patients in doctors' consideration of the potential outcomes of not treating suspected conditions

Phrases that referred to the potential outcomes of missing or not investigating certain diagnoses were counted, on the assumption that a high frequency indicated a raised concern about outcomes, so that a high number for midlife patients would suggest that doctors considered it to be more important not to miss serious diagnoses in the younger age group. This might be because they have assimilated the view, one that is widely and customarily approved, that sustaining the ability of people in midlife to make economic contributions to their quality of life is more important than restoring the quality of life of older people. The results from an analysis of variance revealed, however, an insignificant difference between midlife and older patients in doctors' expressed concerns about the potential outcomes of untreated symptoms (mean scores of I.45 and I.6I respectively). Hypothesis 5 was therefore accepted. There was a significant country effect $(p=0.0 \mathrm{II})$, for US doctors expressed more concerns about the potential outcomes (mean I.9I) than UK doctors (mean I.o8) (see Table 5).

Hypothesis 6: There is no difference between midlife and older patients in doctors' citations of health-care system constraints as reasons for non-intervention

The participating doctors were questioned about the interventions that they would have liked to carry out but, when asked about the interventions 
T A B L E 6. Summary of the results of the hypothesis testing

\begin{tabular}{|c|c|c|c|c|c|}
\hline $\mathrm{H}$ & $\begin{array}{l}\text { Component of } \\
\text { decision-making }\end{array}$ & $\begin{array}{l}\text { Expected frequencies } \\
\text { if no ageism }{ }^{1}\end{array}$ & $\begin{array}{l}\text { Expec- } \\
\text { tation met }\end{array}$ & $\begin{array}{l}\text { Decision } \\
\text { on } \mathrm{H}\end{array}$ & $\begin{array}{l}\text { Evidence } \\
\text { of ageism }\end{array}$ \\
\hline \multicolumn{6}{|c|}{ Classification task $\mathrm{I}$} \\
\hline I & Discrete cues & Equal (not lower for older) & Yes & Accepted & None \\
\hline $2 . \mathrm{I}$ & Frequency of age cues & Higher for older & No & Accepted & Possible \\
\hline 2.2 & $\begin{array}{l}\text { Age associations with } \\
\text { inferences }\end{array}$ & Higher for older & No & Accepted & Possible \\
\hline 3 & Diagnostic inferences & Higher for older & No & Accepted & Possible \\
\hline 4.I & Prototype occurrences & Equal or higher for older & $\mathrm{No}^{2}$ & Rejected & Yes \\
\hline 4.2 & Exemplar occurrences & Equal or higher for older & $\mathrm{No}^{2}$ & Rejected $^{3}$ & $\mathrm{Yes}^{3}$ \\
\hline $4 \cdot 3$ & $\begin{array}{l}\text { Frequency of probability } \\
\text { references }\end{array}$ & Equal & Yes & Accepted & None \\
\hline \multicolumn{6}{|c|}{ Classification task 2} \\
\hline 5 & Potential outcomes & Equal (not lower for older) & Yes & Accepted & None \\
\hline \multicolumn{6}{|c|}{ Classification task 3} \\
\hline & $\begin{array}{l}\text { Healthcare system } \\
\text { constraints }\end{array}$ & Equal (not higher for older) & Yes & Accepted & None \\
\hline
\end{tabular}

Notes: H: Hypothesis (serial number in left-hand column). I. Expected frequencies of the decision-making attribute when consulting with older and midlife patients. 2. Lower frequency for older patients. 3. Rejected only in the United States.

that they would order, did not mention because of local practice constraints. The intention was to gather information about the doctors' views of the ideal interventions that could be made, as opposed to those that were routinely available. It was hypothesised that in consultations with older patients many citations of this reason for non-intervention would evince age-based rationing, so the number of mentioned health-care system constraints was counted. An analysis of variance demonstrated no significant differences by patient age in the frequency of citations of health-care system constraints for non-intervention ( 0.75 for midlife and I.oo for older patients). Hypothesis 6 was therefore accepted, but there was a significant difference between the two countries $(p=$ o.ooI). British doctors cited four times the number (I.39) of health-care system constraints as US doctors (o.33) (see Table 5).

\section{Summary of the results}

Table 6 summarises the results of the tests of the hypotheses for agerelated bias. The columns specify the expected result if ageism was not present, whether or not the expectations were found, and the statistical inferences about whether or not the hypotheses were supported or rejected. On a fine point of statistical inference, it is not correct to translate a failure to reject a hypothesis as proof that it holds. Two results, for Hypotheses 4.I and 4.2 (although only for the US for 4.2), provided no 
support for the hypothesis of no ageism, but the antithesis, that ageism was present, is a possibility not proven (there may be alternative explanations).

\section{Discussion and conclusions}

This paper has focused on the cognitive processes of primary care doctors' patient consultations, and examined the extent to which they promulgate ageism in health-care allocations. The findings demonstrate some systematic differences in their clinical decision-making processes during consultations with older as compared to midlife patients who present with identical CHD clinical symptoms. Overall, however, there was little evidence of indirect ageism, particularly in relation to intervention decisions. Doctors were no more likely to cite health-care system constraints as reasons for non-intervention for older than for midlife patients. Instead, differences between the overall health-care systems in the US and UK had an effect, with UK doctors citing system constraints significantly more often. This was not unexpected, since US health-care expenditure is higher, and US primary-care doctors generally have more in-practice facilities that permit on-site investigation before referrals are required. UK general practitioners, by contrast, face long waiting lists for many important diagnostic tests. On the other hand, US doctors were more influenced by the potential outcomes if treatment was not instigated, presumably due to increased litigation and their widespread practice of defensive medicine, because missing important diagnoses is more likely to lead to patient complaints and serious professional consequences (McKinlay and Marceau 2002).

Diagnosis is the first and fundamental classification task of clinical decision-making. The findings of this study draw attention to the potential for indirect ageism in its practice. Because of the high prevalence of co-morbidity among older patients, it was expected that during the consultations doctors would refer to age more frequently and entertain more diagnostic hypotheses than for midlife patients, but it was found that they were equally mindful of the influence of age for both age groups. It is therefore possible that the doctors did not take full account of older people's disease predispositions during their diagnoses, which amounts to an age-bias in the potential for missing diagnoses.

With respect to the knowledge structures used to represent diseases, the US doctors were significantly less likely to match the information presented by the simulated patients with their experience of actual patients for the older than for the midlife patients. Given the higher likelihood of 
co-morbidity and atypical disease presentations amongst older patients, it was contended that doctors would expect more deviation from textbook descriptions amongst this group, so that matching the presented symptoms with previously experienced cases would happen more frequently. Although the UK doctors did not approach midlife patients with more exemplar representations, both the US and the UK doctors used more prototype representations for this younger group. Overall, therefore, a bias towards more complex pattern matching for midlife patients was shown. Indeed Table 3 shows a tendency for all three types of information about disease categories - prototypes, exemplars and probabilities - to be more frequently referred to when diagnosing the midlife group, albeit only significantly so for prototypes. This may mean that doctors do not work as hard in matching older patients' symptoms with their learned knowledge structures as they do for midlife patients.

Whether the observed differences represent a poorer quality of care is a moot point, not least because 92 per cent of the doctors included CHD among their diagnoses. The variation in the attention that doctors' gave to significant aspects of older patients' presentations may therefore not necessarily have led to erroneous diagnoses and decision-making. It may be that doctors can adjust for patients' age in a way that requires less detailed information and consideration for older than middle-aged patients, and that this does not compromise the diagnoses. This will be tested in future work.

Overall, we believe that our methods of data collection and the classification model of clinical decision-making have demonstrated their usefulness as tools in accessing information about how primary-care doctors' cognitive processes may contribute to indirect ageism. By allowing doctors to describe their decision-making processes in an unstructured way, we have been able to capture linkages between patient cues, data gathering strategies, reasoning processes, methods of data integration, cue weighting and assessments of uncertainty at each of the three stages of clinical decision-making distinguished in the model. Data of this complexity cannot be captured by either structured or semi-structured interviews. Further development of this approach has important implications for medical education, particularly for methods of teaching consultation skills. This paper has demonstrated its ability to expose subtle effects of patients' age and health-care systems on clinical decisionmaking. The analysis was additionally powerful because of the wider study's factorial experimental design, which enabled analysis of doctors' cognitive processes and systematic exploration of the differences between midlife and older patients and between the US and UK health-care systems. 


\section{Acknowledgements}

The research was funded by the United States of America National Institute of Aging (Grant AG-I6747). The authors are grateful to Alan Goroll MD, Ted Stern MD and John Stoeckle MD (Massachusetts General Hospital), David Armstrong PhD, FFPHM, FRCGP and Mark Ashworth MRCP, MRCGP (United Medical and Dental Schools of Guys, Kings and St Thomas's, London), and Diane Ackerley MBBS (Guildford and Waverley Primary Care Trust). We are grateful to Sue Venn for facilitating all aspects of the project in the UK, to our interviewers, Sam Colt and Cathie McColl, and to Nathan Hughes for data entry. We thank all the 256 doctors who gave up an hour of their valuable time to participate in this research. Ann Adams is funded by a Department of Health NGGRCD Primary Care Career Scientist Award.

\section{NOTE}

I Unless otherwise indicated, references later in the paper to statistical significance are at the level of five per cent.

\section{References}

Adbdelhafiz, A. H. 2002. Heart failure in older people: causes, diagnosis and treatment. Age and Ageing, 31, I, 29-36.

Age Concern England 2000. New Survey of GPS Confirms Ageism in the NHS. Press Release, Age Concern England, London, i7 May.

Age Concern England 2002. Age Discrimination. Policy Position Paper, Age Concern England, London. [Available online at http://www.ace.org.uk]

Audit Commission 2002. Integrated Services for Older People. Audit Commission, London.

Black, J. S., Sefcik, T. and Kapoor, W. I990. Health promotion and disease prevention in the elderly. Archives of Internal Medicine, I 5o, 389-93.

Bond, M., Bowling, A., McKee, D., Kennelly, M., Banning, A. P., Dudley, N., Elder, A. and Martin, A. 2003. Does ageism affect the management of ischaemic heart disease? Journal of Health Services Research and Policy, 8, I, 40-7.

Buckingham, C. D. and Adams, A. 2000 . Classifying clinical decision-making: a unifying approach. Fournal of Advanced Nursing, 32, 4, 98I-9.

Buckingham, C. D. and Adams, A. $2000 b$. Classifying clinical decision-making: interpreting nursing intuition, heuristics and medical diagnosis. Fournal of Advanced Nursing, 32, 4, 990-8.

Carmel, S., Galinsky, D. and Cwikel, J. I990. Knowledge, attitudes and work preferences regarding the elderly among medical students and practising physicians. Behavior, Health and Aging, I, 99-104.

Cochran, W. G. and Cox, G. D. 1957. Experimental Designs. Second edition, Wiley, Chichester, Sussex.

Cole, S. A. and Bird, J. 200o. The Medical Interview: The Three-function Approach. Mosby, New York.

Dawes, R. M. I983. Is rationality systematic? Behavioural and Brain Sciences, 3, 491-2.

Department of Health 1991. The Health of the Nation. Her Majesty's Stationery Office (HMSO), London. 
Department of Health 1998. Our Healthier Nation: A Contract for Health. HMSO, London.

Department of Health $2000 a$. The NHS Plan. HMSO, London.

Department of Health $2000 b$. National Service Framework for Coronary Heart Disease: Modern Standards and Service Models. Department of Health, London.

Department of Health 2001. National Service Framework for Older People. HMSO, London.

Department of Health 2002. Liberating the Talents: Helping Primary Care Trusts and Nurses to Deliver the NHS Plan. HMSO, London.

Dudley, N. and Burns, E. I992. The influence of age on policies for admission and thrombolysis in coronary care in the UK. Age and Ageing, 2 I, 95-8.

Gatsonis, C. A., Epstein, A. M., Newhouse, J. P., Normand, S. L. and McNeil, B. J. 1995. Variations in the utilisation of coronary angiography for elderly patients with an acute myocardial infarction: an analysis using hierarchical logistic regression. Medical Care, 33, $6,625-42$.

Glendinning, C., Coleman, A. and Rummery, K. 2002. Partnerships, performance and primary care: developing integrated services for older people in England. Ageing $\mathcal{E}^{\circ}$ Society, 22, I85-208.

Gregoratos, G. 200ı. Clinical manifestations of acute myocardial infarction in older patients. American fournal of Geriatric Cardiology, r o, 6, 345-7.

Hamm, R. M. 2003. Medical decision scripts: combining cognitive scripts and judgment strategies to account fully for medical decision-making. In Hardman, D. and Macchi, L. (eds), Thinking: Psychological Perspectives on Reasoning, Judgment and Decision-making. Wiley, Chichester, 315-45.

Hampton, J. 1993. Prototype models of concept representation. In Mechelen, I. V., Hampton, J., Michalski, R. S. and Theuns, P. (eds), Categories and Concepts: Theoretical Viewes and Inductive Data Analysis. Academic, San Diego, California, 67-95.

Haug, M. R. and Ory, M. G. I987. Issues in elderly patient-provider interactions. Research on Aging, 9, 3-44.

Jarrett, P. G., Rockwood, K., Carver, D., Stolee, P. and Cosway. S. I995. Illness presentation in elderly patients. Archives of Internal Medicine, I55, IO, I060-4.

Johnson, S. M., Kurtz, M. E., Tomlinson, T. and Howe, K. R. I986. Students' stereotypes of patients as barriers to clinical decision-making. Fournal of Medical Education, 6r, 727.

Koehler, J.J. 1996. The base-rate fallacy reconsidered: descriptive, normative and methodological challenges. Behavioural and Brain Sciences, I 9, I-53.

Kruschke, J. K. and Johansson, M. K. I999. A model of probabilistic category learning. Fournal of Experimental Psychology: Learning, Memory and Cognition, 25, 5, 1083-1 I9.

Kwiteck, S. D., Shaver, B. J., Blood, H. and Shepard, D. F. I986. Age bias: physical therapists and older patients. Fournal of Gerontology, 4I , 760.

Laukkanen, P., Sakari-Rantala, R., Kaupinnen, M. and Heikkinen, E. I997. Morbidity and disability in 75- and 8o-year-old men and women: a five year follow-up. Scandinavian Fournal of Social Medicine, 53, supplement, 79-106.

Levy, B. R. 200I. Eradication of ageism requires tackling the enemy within. The Gerontologist, 4I , 5, 578-9.

Little, P., Slocock, L., Griffin, S. and Pillinger, J. I999. Who is targeted for lifestyle advice? A cross-sectional study in two general practices. British Fournal of General Practice, 49, 447, 8o6-Io.

McKinlay, J. B. and Marceau, L. 2002. The end of the golden age of doctoring. International Fournal of Health Services, 32, 2, 379-416.

McKinlay, J. B., Potter, D. A. and Feldman, H. A. 1996. Non-medical influences on medical decision-making. Social Science and Medicine, 42, 5, 769-76.

McKinlay, J. B., Lin, T., Freund, K. and Moskowitz, M. 2002. The unexpected influence of physician attributes on clinical decisions: results of an experiment. Fournal of Health and Social Behaviour, 43, 92-106. 
McKinlay, J. B., Burns, R. B., Durante, R., Feldman, H. A., Freund, K. M., Harrow, B. S., Irish, J. T., Kasten, L. E. and Moskowitz, M. A. I997. Patient, physician and presentational influences on clinical decision-making for breast cancer: results from a factorial experiment. Fournal of Evaluation in Clinical Practice, 3, I-69.

McKinstry, B. 2000. Do patients wish to be involved in decision-making in the consultation? A cross-sectional survey with video vignettes. British Medical fournal, 32 I, 7265 , 867-7I.

McLaughlin, T. J, Soumerai, S. B. and Wilson, D. J. I996. Adherence to national guidelines for drug treatment of suspected acute myocardial infarction. Archives of Internal Medicine, $\mathbf{1 5 6 , 7 9 9 - 8 0 5 . ~}$

National Centre for Health Statistics 2002. Health, US. National Gentre for Health Statistics, Washington DC.

National Institute of Aging 2000. Strategic Plan to Address Health Disparities in Aging: Fiscal Years 2000-2005. National Institute of Aging, Bethesda, Maryland.

Neighbour, R. I987. The Inner Consultation. MTP Press, Lancaster, Lancashire.

Priebe, H. J. 2000. The aged cardiovascular risk patient. British Fournal of Anaesthesia, 85, 5, $763-78$.

Roberts, E., Robinson, J. and Seymour, L. 2002. Old Habits Die Hard: Tackling Age Discrimination in Health and Social Care. King's Fund, London.

Shaw, L. J., Miller, D. D., Romeis, J. C., Younis, L. T., Gillespie, K. N., Kimmey, J. R. and Chaitman, B. R. I996. Prognostic value of non-invasive risk stratification in younger and older patients referred for evaluation of suspected coronary artery disease. Fournal of the American Geriatrics Society, 44, I0, II90-7.

Silverman, J., Kurtz, S. and Draper, J. 1998. Skills for Communicating with Patients. Radcliffe Medical Press, Oxford.

Soumerai, S. B., McLaughlin, T.J. and Speigelman, D. 1997. Adverse outcomes of underuse of beta-blockers in elderly survivors of acute myocardial infarction. Fournal of the American Medical Association, 277, II5-21.

Stafford, R. S. and Singer, D. E. I996. National patterns of warfarin use in atrial fibrillation. Archives of Internal Medicine, I 56, 2537-4I.

Tarbox, A. R., Connors, G. J. and Faillace, L. A. 1987. Freshmen and senior medical students' attitudes towards the elderly. Fournal of Medical Education, 62, 582.

Tresch, D. D. and Alla, H. R. 200I. Diagnosis and management of myocardial ischaemia (angina) in the elderly patient. American Fournal of Geriatric Cardiology, וo, 6, 337-44.

Address for correspondence:

Accepted 20 June 2005

Centre for Primary Health Care Studies, Warwick Medical School, University of Warwick, Coventry $\mathrm{CV}_{4}$ 7AL, UK.

e-mail: a.e.adams@warwick.ac.uk 